\title{
Response Surface Methodology for the Optimization of Coco-ethanolamide Production From Coconut oil
}

\section{ZUHRINA MASYITHAH $^{1 *}$, DINAR RAJAGUKGUK ${ }^{1}$, SAMUEL OKTAVIANUS PURBA ${ }^{1}$ and ARMANSYAH GINTING ${ }^{2}$}

\author{
'Department of Chemical Engineering, Faculty of Engineering, Universitas Sumatera Utara, \\ Jalan Almamater, Medan 20155, Indonesia. \\ ${ }^{2}$ Department of Mechanical Engineering, Faculty of Engineering, Universitas Sumatera Utara, \\ Jalan Almamater, Medan 20155, Indonesia. \\ *Corresponding author E-mail: zuhrina@yahoo.com
}

http://dx.doi.org/10.13005/ojc/340644

Received: October 02, 2018; Accepted: December 06, 2018)

\begin{abstract}
Coco ethanolamide obtained from the amidation of fatty acid methyl ester (FAME) from coconut oil with mono ethanolamine using zirconium (IV) chloride and tert-amyl alcohol was observed in this study. Several effective parameters were evaluated in term of catalyst concentration $(5-9 \%$ w/wFAME), reaction temperature $\left(80-100^{\circ} \mathrm{C}\right)$ and stirring speed $(200-400 \mathrm{rpm})$. Response Surface Methodology (RSM) was used to optimize and to observe the interaction effects of the three variables on the FAME conversion. The capability of the process was measured from the number of FAME converted to coco ethanolamide. In the range of parameters evaluated, the conversion increase by increasing the catalyst concentration up to $9 \%$ (w/wFAME), but decreases after the optimum value. At the optimal condition, the model predicts a maximum FAME conversion of $86.27 \%$, mainly due to a strong interaction between catalyst concentration and stirring speed.
\end{abstract}

Keywords: Coco ethanolamide, Coconut oil, Zirconium (IV) chloride, Response Surface Methodology.

\section{INTRODUCTION}

The production and utilization of environmentally friendly surfactants are growing in line with their increasing consumption lately. For this reason, a more efficient method and the use of renewable raw materials is a research advantage in the field of surfactants ${ }^{1}$. So the requirements for modern surfactants are quite heavy, such as having high efficiency, non-toxic (at least only slightly toxic), as well as renewable and biodegradable ${ }^{2,3}$.

Alkanolamide is a condensation product between alkanolamines and fatty acids, methyl esters or triglycerides. Alkanolamide is a non-ionic surfactant that can be used to change surface properties by absorbing or concentrating on the surface or liquid interface and reducing surface tension ${ }^{4,5}$. Fatty acid ethanolamide is a very important class of alkanolamide surfactants. These

This is an Open Access article licensed under a Creative Commons license: Attribution 4.0 International (CC- BY). Published by Oriental Scientific Publishing Company @ 2018 
surfactant groups are widely used as lubricants, detergents, and cosmetics ${ }^{6}$. Their physicochemical properties can vary depending on the length of the hydrocarbon chain ${ }^{7,8}$.

Coconut (Cocos nucifera L.) is an important plant in the world that provides benefits to millions of people, especially in tropical and subtropical regions. ${ }^{9}$. Coconut oil mainly consists of lauric acid $45-52 \%$, myristic acid $16-21 \%$, caprylic acid $5-10 \%$, caproic acid $0.5-1 \%$, and other components such as palmitic acid, oleic acid, linoleic acid, stearic acid, vitamin $\mathrm{E}$ and protein. All of these components provide health benefits ${ }^{10,11}$.

Coco ethanolamide is a mixture of ethanolamide from coconut fatty acid, which is generally in the form of radical structures (RCO-). Coconut fatty acids derived from coconut oil transesterification are then amidized with monoethanolamine to produce coco ethanolamide using homogeneous and heterogeneous catalysts. 12,13. Monoethanolamine (MEA) or often referred to as 2-aminoethanol or ethanolamine is an amino alcohol which is hygroscopic with an ammonia odor. Monoalkanoamine is often used for the absorption of acid gases such as carbon dioxide in a gas chimney in the oil and gas industry ${ }^{14}$.

The recent use of heterogeneous catalysts from metal is an appropriate and attractive alternative because of low consumption, environmentally friendly use, and easy separation process ${ }^{15}$. One of the heterogeneous catalysts that are widely used is zirconium (IV) chloride. Zirconium (IV) chloride is an efficient metal catalyst and can be used in the direct oxidation reaction of non-activated carboxylic acids with primary and secondary amines ${ }^{8}$. This catalyst is a compound that is considered non-toxic, is widely available in the earth's crust, and because it is solid, makes it easy to recycle ${ }^{16}$.

On the basis of the theory that has been presented, the research on the synthesis of coco ethanolamide surfactant from coconut oil and monoethanolamine, through an amidation reaction using $\mathrm{ZrCl}_{4}$ catalyst, is carried out to obtain important information about the effect of the catalyst concentration, reaction temperature and stirring speed on the surfactant produced.

\section{MATERIALS AND METHODS}

\section{Materials}

The coconut oil used as a commercial oil that is Braco®. Methanol $\left(\mathrm{CH}_{3} \mathrm{OH}\right)$, sodium hydroxide $(\mathrm{NaOH})$, monoethanolamine $\left(\mathrm{CH}_{2}(\mathrm{OH})\right.$ $\left.\mathrm{CH}_{2} \mathrm{NH}_{2}\right)$, zirconium (IV) chloride $\left(\mathrm{ZrCl}_{4}\right)$, tert-amyl alcohol $\left(\mathrm{C}_{5} \mathrm{H}_{12} \mathrm{O}\right)$, potassium hydroxide $(\mathrm{KOH})$, phenolphthalein $\left(\mathrm{C}_{20} \mathrm{H}_{14} \mathrm{O}_{4}\right)$, ethanol $\left(\mathrm{CH}_{3} \mathrm{CH}_{2} \mathrm{OH}\right)$ and chloride acid $(\mathrm{HCl})$ are obtained from $\mathrm{E}$ Merck, Darmstadt Germany.

\section{Transesterification of coconut oil to FAME}

The transesterification process carried out is as follows ${ }^{17,18}$. In the three-neck flask, $100 \mathrm{~g}$ of coconut oil are put in and heated to a temperature of $60^{\circ} \mathrm{C}$. Then $1 \% \mathrm{NaOH}$ is added (w/w Coconut Oil) which has been dissolved in $\mathrm{CH}_{3} \mathrm{OH}$ with a mole ratio of methanol to coconut oil 6/1. Stir for 1 (one) hour, and then the mixture is put into a separating funnel. Left to form two layers. The top layer is washed with hot water and shaken to extract impurities. Then the methyl esters obtained were analyzed using FTIR and GC.

\section{Synthesis of coco ethanolamide}

The reaction was carried out using a three-neck flask. The reaction flask was equipped with a condenser, thermometer and a magnetic stirrer. Variables and levels developed for coco ethanolamide synthesis are given in Table 1. The experimental design used is Central Composite Design (CCD) ${ }^{19,20}$. FAME was blended with 5-9\% (w/wFAME) $\mathrm{ZrCl}_{4}$ to react with MEA at the molar ratio of $3 / 1$ (MEA/FAME). The reaction was carried out at $80-100^{\circ} \mathrm{C}$ and $200-400 \mathrm{rpm}$ for 3 hours. The blend of starting materials and reaction condition was the optimal condition based on the previous study on the synthesis of fatty ethanolamides. The mixture was separated from the catalyst by filtration, the solvent and methanol were evaporated by a distillation method. Determination of functional groups contained in coco ethanolamide surfactant was carried out using FT-IR. 
Table 1: Variables and levels developed for coco ethanolamide synthesis

\begin{tabular}{lccccc}
\hline Variables & Levels & & & & \\
& -1.682 & -1 & 0 & 1 & 1.682 \\
\hline $\begin{array}{l}\text { Catalyst Concentration } \\
\left(\mathrm{X}_{1}, \text { w/wFAME) }\right.\end{array}$ & 3.6364 & 5 & 7 & 9 & 10.3636 \\
$\begin{array}{l}\text { Reaction Temperature } \\
\left(\mathrm{X}_{2}{ }^{\circ} \mathrm{C}\right)\end{array}$ & 73.182 & 80 & 90 & 100 & 106.818 \\
Stirring Speed $\left(\mathrm{X}_{3}, \mathrm{rpm}\right)$ & 131.821 & 200 & 300 & 400 & 468.179 \\
\hline
\end{tabular}

\section{RESULTS AND DISCUSSION}

\section{Transesterification of Coconut Oil}

In this study, a transesterification reaction was first carried out to produce methyl esters from coconut oil. Transesterification of coconut oil with alcohol will form fatty acid methyl esters (FAME) and glycerol as by-products. In principle, one alcohol replaces another ester group, which is called alcoholysis (replacement of the alcohol group). Transesterification is a reversible reaction so that excess alcohol is usually used to shift the equilibrium to the side of the product ${ }^{17}$.

Furthermore, FTIR analysis was carried out on fatty acid methyl ester products. The spectrum is obtained in the form of absorption peaks in the wavenumber region $1740.65 \mathrm{~cm}^{-1}$, where it shows the presence of a group $\mathrm{C}=\mathrm{O}$ which is an ester group. The $\mathrm{C}=\mathrm{O}$ bond vibration for the ester is in the wave number $1735-1750 \mathrm{~cm}^{-1} 21,22$. The fatty acid methyl ester components were determined by GC. FAME conversion from coconut oil obtained was $78.27 \%$.

\section{Effect of reaction temperature}

The study was started by synthesizing coco monoethanolamide surfactants from coconut oil methyl ester and monoethanolamine. The variables observed were temperature and catalyst concentration.

The relationship between the reaction temperature to the FAME conversion is shown in Fig. 1. Observations show that FAME conversion will increase as the reaction temperature increases to a certain extent, then it will be constant or decrease. It was seen that the amidation reaction that took place at a temperature of $80^{\circ} \mathrm{C}$ with a catalyst concentration of $9 \%$ there was a decrease in conversion, as well as at a temperature of $90^{\circ} \mathrm{C}$ with a catalyst concentration of $3 \%$ and a temperature of $1000 \mathrm{C}$ with a catalyst concentration of $7 \%$ and $9 \%$.
Figure 1 also shows that the maximum conversion is obtained at several different catalyst temperature and concentration values. It is obtained that if the temperature is $60^{\circ} \mathrm{C}$ and the catalyst concentration is $9 \%$, a conversion of $84.75 \%$ will be obtained. At a temperature of $70^{\circ} \mathrm{C}$ and a catalyst concentration of $9 \%$ a conversion of $88.14 \%$ was obtained. Likewise, at $80^{\circ} \mathrm{C}$ and $5 \%$ catalyst concentration, $86.44 \%$ conversion was obtained. And at a temperature of $90^{\circ} \mathrm{C}$ and a catalyst concentration of $7 \%, 89.83 \%$ conversion was obtained. Because of the difficulty of determining an optimum value that will produce the maximum conversion, it is necessary to continue optimizing this process condition using the Response Surface Methodology ${ }^{19,20}$.

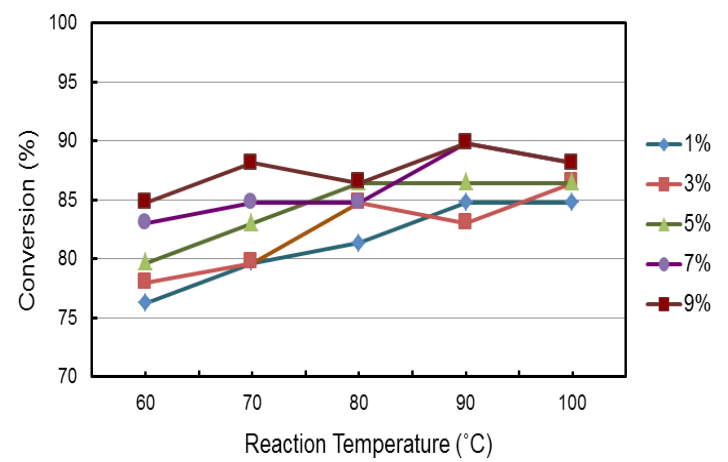

Fig. 1. The relationship between the reaction temperature to the FAME conversion

\section{Effect of Catalyst Concentration}

The graph of the relationship between catalyst concentration and FAME conversion is shown in Fig. 2. Observations show that FAME conversion will increase to a certain extent as the catalyst concentration increases, then it will be constant or decrease if it reaches a certain point. In the amidation reaction that took place at a catalyst concentration of $7 \%$ and a temperature of $80^{\circ} \mathrm{C}$, there was a decrease in conversion, as well as at a catalyst concentration of $3 \%$ and a temperature of $90^{\circ} \mathrm{C}$. 
Figure 2 also shows that the maximum conversion is obtained in certain conditions. Where if the catalyst concentration is $1 \%$ at a reaction temperature of $100^{\circ} \mathrm{C}$, conversion of $84.75 \%$ will be obtained, and at a catalyst concentration of $7 \%$ and temperature of $90^{\circ} \mathrm{C}$ will be obtained FAME conversion of $89.83 \%$. Likewise, at a catalyst concentration of $9 \%$ and a temperature of $90^{\circ} \mathrm{C}$, a conversion of $89.83 \%$ will also be obtained.

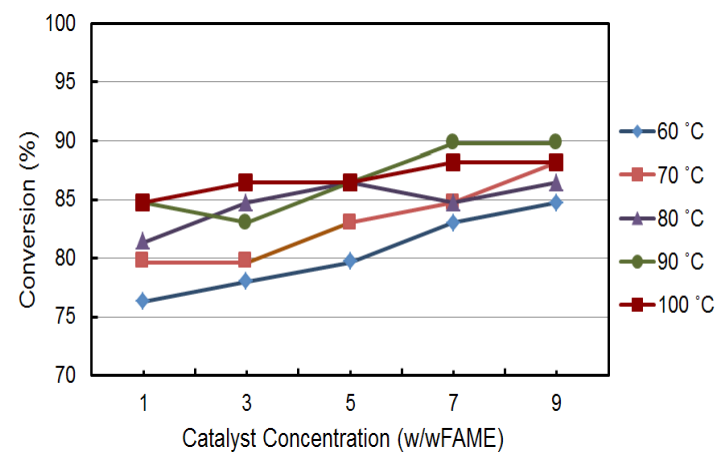

Fig. 2. The relationship between the catalyst concentration to the FAME conversion

Although a value cannot be determined as a recommendation to get the maximum conversion, Fig. 2 shows that overall FAME conversion will increase as the catalyst concentration increases ${ }^{12}$. The deviations that occur may be caused by the presence of a catalyst that is not mixed or the reaction temperature is not constant.

Effect of Interaction between Stirring Speed, Temperature and Catalyst Concentration

Optimization of the production of coco ethanolamide surfactants was carried out using RSM and Central Composite Design (CCD). The results of coco ethanolamide synthesis are shown in Table 2. The following equation shows the relationship between catalyst concentration $\left(X_{1}\right)$, reaction temperature $\left(X_{2}\right)$ and stirring speed $\left(X_{3}\right)$ against the percent conversion of FAME $(\mathrm{Y})$.

$\mathrm{Y}=86.27+0.2456 \mathrm{X}_{1}+2.3072 \mathrm{X}_{2}+2.4204 \mathrm{X}_{3}-$ $5.2892 X_{12}-0.8742 X_{22}-8.2292 X_{32}-3.1219 X_{1} \cdot X_{2}-$ $9.3586 \mathrm{X}_{1 .} \mathrm{X}_{3}-5.1937 \mathrm{X}_{2} \mathrm{X}_{3}$

The results of the regression coefficients analysis of coco ethanolamide synthesis are shown in Table 3. From the results in Table 3, it was found that catalyst concentration and stirring speed had a positive and very significant effect on increasing
FAME conversion. The reaction temperature also had a positive effect, but it was not significant to the increase in yield.

Table 2: The results of coco ethanolamide synthesis

\begin{tabular}{ccccc}
\hline No. & $\begin{array}{c}\text { Catalyst } \\
\text { Concentration } \\
\left(\mathrm{X}_{1}, \text { w/wFAME }\right)\end{array}$ & $\begin{array}{c}\text { Reaction } \\
\text { Temperature } \\
\left(\mathrm{X}_{2},{ }^{\circ} \mathrm{C}\right)\end{array}$ & $\begin{array}{c}\text { Stirring } \\
\text { Speed } \\
\left(\mathrm{X}_{3}, \mathrm{rpm}\right)\end{array}$ & $\begin{array}{c}\text { Conversion } \\
(\mathrm{Y}, \%)\end{array}$ \\
\hline 1 & -1 & -1 & -1 & 73.53 \\
2 & 1 & -1 & -1 & 79.41 \\
3 & -1 & 1 & -1 & 79.41 \\
4 & 1 & 1 & -1 & 85.29 \\
5 & -1 & -1 & 1 & 85.29 \\
6 & 1 & -1 & 1 & 82.35 \\
7 & -1 & 1 & 1 & 88.24 \\
8 & 1 & 1 & 1 & 76.47 \\
9 & -1.682 & 0 & 0 & 79.41 \\
10 & 1.682 & 0 & 0 & 82.35 \\
11 & 0 & -1.682 & 0 & 82.35 \\
12 & 0 & 1.682 & 0 & 88.24 \\
13 & 0 & 0 & -1.682 & 76.47 \\
14 & 0 & 0 & 1.682 & 79.41 \\
15 & 0 & 0 & 0 & 85.29 \\
16 & 0 & 0 & 0 & 85.29 \\
17 & 0 & 0 & 0 & 85.29 \\
18 & 0 & 0 & 0 & 85.29 \\
19 & 0 & 0 & 0 & 88.24 \\
20 & 0 & 0 & 0 & 88.24 \\
\hline & & & & \\
\hline
\end{tabular}

Table 3: The results of regression coefficients analysis of coco ethanolamide

\begin{tabular}{lcc}
\hline Term & Coef & $P$ \\
\hline Constant $(Y)$ & 86.2677 & 0.000 \\
Catalyst $\left(X_{1}\right)$ & 0.2456 & 0.766 \\
Temperature $\left(X_{2}\right)$ & 2.3072 & 0.016 \\
Stirring speed $\left(X_{3}\right)$ & 2.4204 & 0.013 \\
$\left(X_{1}\right)^{*}\left(X_{1}\right)$ & -5.2892 & 0.002 \\
$\left(X_{2}\right)^{*}\left(X_{2}\right)$ & -0.8742 & 0.520 \\
$\left(X_{3}\right)^{*}\left(X_{3}\right)$ & -8.2292 & 0.000 \\
$\left(X_{1}\right)^{*}\left(X_{2}\right)$ & -3.1219 & 0.107 \\
$\left(X_{1}\right)^{*}\left(X_{3}\right)$ & -9.3586 & 0.000 \\
$\left(X_{2}\right)^{*}\left(X_{3}\right)$ & -5.1937 & 0.015 \\
\hline
\end{tabular}

$\mathrm{R}$-Sq $=$ total squared $=91.57 \%$

$\mathrm{R}-\mathrm{Sq}(\mathrm{adj})=$ squares due to treatment $=83.98 \%$

Figure 3 shows the plot of the surface and contour response in observing the interaction effect between reaction temperature and catalyst concentration on FAME conversion. Overall it was found that FAME conversion would increase in 
line with the increase in temperature and catalyst concentration. The interaction effect on increasing the temperature and catalyst to the maximum value will actually slightly reduce the reaction conversion. This decrease occurs due to reduced ammonia solubility in the fluid as temperature increases ${ }^{23}$. Likewise in this reaction, an increase in temperature allows reduced solubility of amines in the ester which will affect the conversion of the reaction.
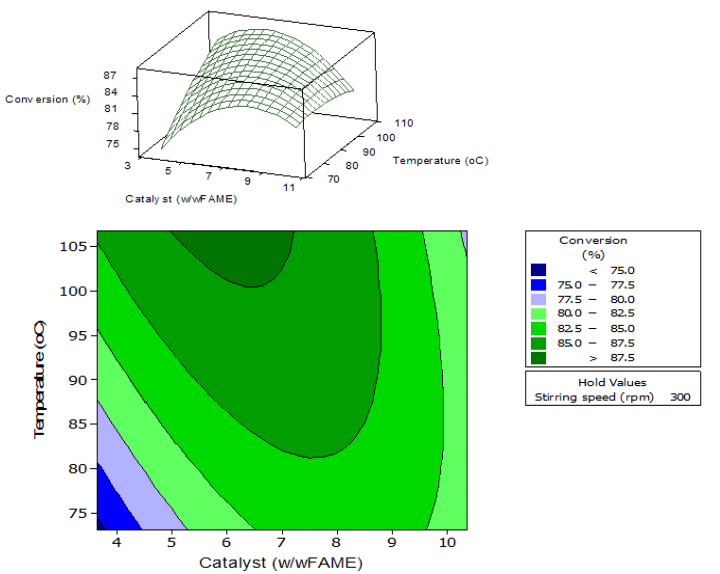

Fig. 3. The interation effect between reaction temperature and catalyst concentration on FAME conversion

The best reaction conditions in this reaction are if the temperature is in the range of $85-95^{\circ} \mathrm{C}$ and the catalyst concentration is $5-7 \%$ (w/wFAME). This is because the boiling point of the tert-amyl alcohol solvent used is $103^{\circ} \mathrm{C}$, so if the reaction temperature used is more than $100^{\circ} \mathrm{C}$ there is a possibility that the solvent will evaporate which results in reduced contact between reactants which will affect the ongoing amidation reaction ${ }^{3}$.

The choice of zirconium (IV) chloride catalyst is because $\mathrm{Zr}^{4+}$ has a strong coordinating ability that allows them to produce very good reactions and can work well in various solvents ${ }^{15,16}$. By increasing the catalyst concentration, it increases the active catalytic concentration and in this case the reaction rate re. $^{23}$.

The interaction effect between stirring speed and catalyst concentration is given in Fig. 4. It can be seen that the optimum conditions obtained from this interaction are at a stirring speed of 250-450 rpm and a catalyst concentration of 4-8\% (w/wFAME). The conversion decline occurs after the optimum conditions are achieved, it seems that it is caused by the formation of alcohol as a by-product which will cause the nucleophilic attack and an intermediate giving that can lose the proton to form a new ester. Since the reaction between carbonation and alcohol can produce esters, it has been proposed that this reaction should be performed in the absence of alcohol ${ }^{12}$.
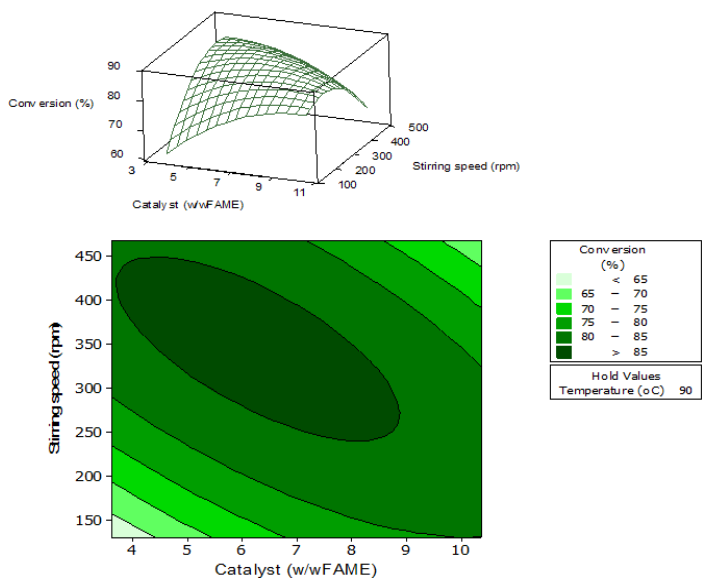

Fig. 4. The interation effect between stirring speed and catalyst concentration on FAME conversion

The interaction effect between stirring speed and reaction temperature is given in Fig. 5. The maximum FAME conversion is obtained at a stirring speed of 200-350 rpm and temperature of $80-100^{\circ} \mathrm{C}$. Increased stirring speed looks more significant in increasing percent FAME conversion compared to temperature.

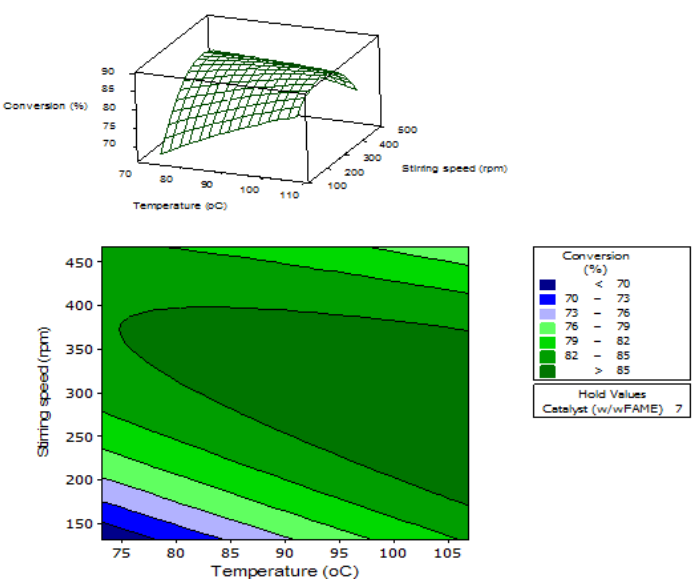

Fig. 5. The interation effect between stirring speed and reaction temperature on FAME conversion

After observing the three contour plots, the relationship between stirring speed, catalyst concentration and reaction temperature to FAME conversion, it can be concluded that the optimum 
value of stirring speed of $350 \mathrm{rpm}$, catalyst concentration of $6 \%$ (w/wFAME) and reaction temperature of $90^{\circ} \mathrm{C}$ will be obtained maximum FAME conversion between $85-88 \%$.

\section{Identification Analysis of Coco Ethanolamide with FT-IR Spectroscopy}

Electromagnetic radiation that interacts with a substance can be absorbed, transmitted and reflected which can provide important information on molecular structures and the transition of energy levels of the substance ${ }^{21}$. The results of the FT-IR cocamide ethanolamine obtained Fig. 6 shows the results of FT-IR spectrum analysis at a catalyst concentration of $7 \%$ (w/wFAME) and temperature of $90^{\circ} \mathrm{C}$. The results of this reaction were purified by purification procedure and then analyzed by FT-IR. It

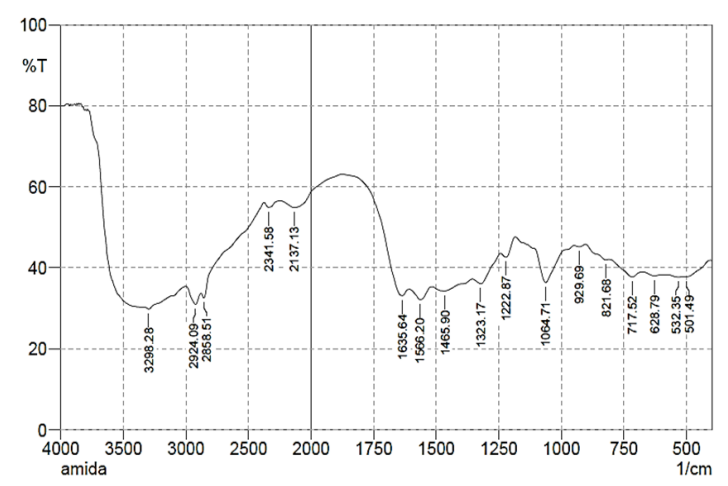

Fig. 6. The results of the FT-IR cocamide ethanolamine can be seen that the vibration of the $\mathrm{C}=\mathrm{O}$ bond for amide is in the wave number $1630-1680 \mathrm{~cm}^{-121}$. The spectrum in Fig. 6 shows the absorption peak in the wave number area $1635.64 \mathrm{~cm}^{-1}$, where it shows the presence of a group $\mathrm{C}=\mathrm{O}$ which is an amide group.

\section{CONCLUSION}

In this study, coco ethanolamide was obtained from the transesterification of coconut oil and continued with amidation of FAME with monoethanolamine. Process optimization can be obtained using RSM and CCD. Of the three main parameters observed, stirring speed and catalyst concentration had a positive and highly significant in an increase of FAME conversion. However, the reaction temperature variable also has a positive effect but less significant on the coco ethanolamide produced. This study shows that transesterification followed by amidation using zirconium (IV) chloride catalysts can be performed optimally to obtain maximum coco ethanolamide.

\section{ACKNOWLEDGMENT}

This research is funded by Directorate of Research and Community Service, Directorate General of Research and Development, Ministry of Research, Technology and Higher Education, the fiscal year 2018.

\section{REFERENCES}

1. Shoeb, E.; Akhlaq, F.; Badar, U.; Akhter, J.; Imtiaz, S. Malaysian J. Anal. Sci., 2016, 20, 31-43.

2. Brica, S.; Klavins, M.; Andris, Z. Green Sustainable Chem., 2016, 6, 125-135.

3. Masyithah, Z.; Orient. J. Chem., 2016, 32, 1361-1371.

4. Swadesi, B.; Marhaendrajana, T.; Siregar, H.P.S.; Mucharam, L. J. Eng. Technol. Sci., 2015, 47, 250-265.

5. Masyithah, Z.; Herawan, T. J. Pure. App. Microbiol., 2017, 11, 1327-1336.

6. Lee, C.S.; Lee, S.C. Am. J. Pharmacol. Toxicol., 2010, 5, 133-138.

7. Lokhande, A.R.; Patil, V. S.; Wani, K.S. Int. J. Eng. Dev. Res., 2016, 4, 1088-1092.
8. Tinnis, F.; Lunberg, H.; Adolfsson, H. AdV. Synth. Catal., 2012, 354, 1-7.

9. DebMandal, M.; Mandal, S. Asian Pac. J. Trop. Med., 2011, 4, 241-247.

10. Loomba, S.; Jothi, V. Int. J. Sci. Study., 2013, 1, 138-140.

11. Vala, G.S.; Kapadiya, P.K. Int. J. Life Sci. Res., 2014, 2, 124-126.

12. Kouchak, Y.Z., Alemzadeh, I. Int. J. Eng., Trans. A., 2016, 29, 436-443.

13. Masyithah, Z. Orient. J. Chem., 2017, 33, 3069-3076.

14. Maszelan, C.N.H.C.; Buang, A. Appl. Mech. Mater., 2014, 625, 792-795.

15. Lunberg, H.; Tinnis, F.; Adolfsson, H. Chem. Eur. J., 2012, 18, 3822 - 3826. 
16. Smitha, G.; Chandrasekhar, F.; Reddy, C.S. Synthesis., 2008, 6, 829-835.

17. Bressani, A.P.P.; Garcia, K.C.A.; Hirata, D.B.; Mendes, A.A. Bioprocess Biosyst. Eng., 2015, 38, 287-297.

18. Ayetor, G.K.; Sunnu, A.; Parbey, J. Alexandria Eng. J., 2015, 54, 1285-1290.

19. Hosseini, S.; Tarzi, B.G.; Gharachorloo, M.; Ghavami, M.; Bakhoda, H. Orient. J. Chem., 2015, 31, 1223-1230.

20. Masyithah, Z.; Ginting, A. Orient. J. Chem.,
2018, 34, 1249-1256.

21. Silverstein, R.M.; Webster, F.X.; Kiemle, D.J. Spectrometric identification of organic compounds. 2005. Seventh Edition. State University of New York. John Wiley and Sons Inc. New York.

22. Sheibani, A.; Ghotbaddini-Bahraman, N.; Sadeghi, F. Orient. J. Chem., 2014, 30, 12051209.

23. Kaur, R.; Machiraju, R.; Nigam, K.D.P. Can, J. Chem. Eng. 2008, 86, DOI 10.1002/cje.2013. 